\title{
Safety and Efficacy of a Novel Everolimus-Eluting Stent System in "Real-World" Patients with Coronary Artery Disease: A Report of Preliminary Outcomes
}

\author{
Sridhar Kasturi' ${ }^{1}$, Srinivas Polasa ${ }^{2}$, Shailender Singh ${ }^{1}$, Vijay Kumar Reddy ${ }^{1}$, Kondal Rao1, \\ Ganesh Mathan', Shiva Kumar Bandimida', Manikandhar Pendyala1, Chandrashekar Challa ${ }^{1}$ \\ ${ }^{1}$ Sunshine Heart Institute, Secunderabad, India \\ ${ }^{2}$ Chalmeda Anandrao Institute of Medical Sciences, Karimnagar, India \\ Email: sridharkasturi@yahoo.com
}

How to cite this paper: Kasturi, S., Polasa, S., Singh, S., Reddy, V.K., Rao, K., Mathan, G., Bandimida, S.K., Pendyala, M. and Challa, C. (2016) Safety and Efficacy of a Novel Everolimus-Eluting Stent System in "RealWorld" Patients with Coronary Artery Disease: A Report of Preliminary Outcomes. World Journal of Cardiovascular Diseases, 6, 458-467.

http://dx.doi.org/10.4236/wjcd.2016.612049

Received: October 16, 2016

Accepted: December 16, 2016

Published: December 19, 2016

Copyright $\odot 2016$ by authors and Scientific Research Publishing Inc. This work is licensed under the Creative Commons Attribution International License (CC BY 4.0).

http://creativecommons.org/licenses/by/4.0/

(c) (i) Open Access

\begin{abstract}
Introduction: Tetrilimus (Sahajanand Medical Technologies Pvt. Ltd., Surat, India) is a recently-introduced biodegradable-polymer coated everolimus-eluting cobaltchromium coronary stent system with an ultra-thin strut thickness. We aimed to evaluate the clinical outcomes with Tetrilimus coronary stents in "real-world" patients with coronary artery disease. Methods: In this retrospective, single-arm, openlabel, multi-center registry, all consecutive patients who received Tetrilimus stents between July-2015 and April-2016 at two tertiary-care centers in India were analyzed. Primary endpoint was 30-day incidence of major adverse cardiac events (MACE), defined as a composite of cardiac death, myocardial infarction, target lesion revascularization, and target vessel revascularization. The Academic Research Consortium (ARC)-defined stent thrombosis was assessed as additional safety endpoint. Results: During the study period, 280 Tetrilimus stents (1.4 \pm 0.5 stent/patient $)$ were implanted to treat 252 coronary lesions $(1.1 \pm 0.3$ stent/lesion) in 208 patients (age: 57.5 \pm 11.9 years). Of study population, $65.9 \%$ were males, $46.6 \%$ were hypertensives, $25 \%$ were diabetics, $36.5 \%$ were alcoholics, $29.3 \%$ were smokers, $13.9 \%$ were tobacco chewers, $5.3 \%$ had previous revascularization, and $45.2 \%$ displayed multi-vessel disease. Of treated lesions, $67.5 \%$ were complex and $18.7 \%$ had total occlusion. Average length and diameter of implanted stents were $25.5 \pm 8.8 \mathrm{~mm}$ and $2.9 \pm 0.3 \mathrm{~mm}$ respectively. Subsequently, 30-day MACE were reported in $2(0.96 \%)$ patients; both cases owing to in-hospital cardiac deaths. Events of stent thrombosis or noncardiac death were not reported in any patient. Conclusion: Low MACE rates and absence of stent thrombosis at early 30 -day follow-up indicates that Tetrilimus everolimus-
\end{abstract}


eluting stents may have encouraging safety and efficacy in unselected "real-world" patients with coronary artery disease.

\section{Keywords}

Biodegradable Polymer, Percutaneous Coronary Intervention, Everolimus-Eluting Stent, Ultra-Thin Strut, Major Adverse Cardiac Event, Stent Thrombosis

\section{Introduction}

Drug-eluting stents (DES) are milestone development in the field of interventional cardiology, due to their ability to reduce the risk of restenosis and repeat revascularization after percutaneous coronary intervention [1]. However, delayed stent thrombosis (ST) and restenosis remains a significant concern in patients treated with DES implantations, particularly with DES having permanent polymers [2] [3] [4]. Biodegradable polymers have been developed as an answer to this concern. These polymers afford a controlled release of anti-restenotic agents and gradual degradation of the coating, which ultimately provide the safety of bare-metal stents and the efficacy of DES after stenting [5] [6]. In addition, the role of strut thickness has also been considered to play a major role in clinical outcomes after DES implantation. The conventional stents comprised thick strut platforms, which have been implicated in worse vessel response to the mechanical trauma induced by the dilation process [7] [8]. Progressively, thinner strut stents have been developed to enhance the biocompatibility of these stents [8] [9]. Based on this consideration, DES with ultra-thin strut design and biodegradable polymer coatings have been developed in recent years. Tetrilimus everolimus-eluting coronary stent (Sahajanand Medical Technologies Pvt. Ltd., Surat, India) is one such novel DES with biodegradable polymer coating, designed using an ultra-thin $(60 \mu \mathrm{m})$ cobalt-chromium stent platform. The present registry was designed to assess the short-term and longterm clinical outcomes of the Tetrilimus everolimus-eluting coronary stent in a realworld patient population. In the present report, we present a preliminary report of 30day outcomes with study stent.

\section{Methods}

\subsection{Study Design and Patient Population}

This was a retrospective, singe-arm, multi-center study conducted at Sunshine Heart Institute, Secunderabad, India and at Chalmeda Anandrao Institute of Medical Sciences, Karimnagar, India. The present study report included examination of consecutive patients diagnosed with significant coronary lesions and who underwent PCI with Tetrilimus coronary stent system between July-2015 and April-2016. Inclusion criteria comprised all patients who received at least one Tetrilimus everolimus-eluting stent and a willingness to sign informed consent. No additional clinical or angiographic exclusion criteria were defined. In brief, the inclusion criteria included: 1) patients aged $\geq$ 
18 years; 2) patients undergoing PCI with at least one Tetrilimus everolimus-eluting coronary stent; 3) patients who offered a signed informed consent for data release; and 4) patients with geographical stability and willingness to participate at all follow-up assessments. Exclusion criteria included 1) patient who received more than one stent, which is not a Tetrilimus everolimus-eluting coronary stent within the same/other vessel during index procedure or 6 months prior to index procedure; 2) pregnant patients; 3) patients with known intolerance to aspirin, clopidogrel, ticlopidine, heparin or any other anticoagulation/antiplatelet therapy required for PCI; 4) patients with known allergy to cobalt-chromium, everolimus or contrast media; 5) patients undergoing planned CABG or additional PCI within the first 6 months after the procedure; 6) patients currently participating in another study for which the primary endpoint is not reached yet. Written informed consents were obtained from each enrolled patient. The study protocol was approved by the Institutional Ethics Committee and the study conformed to the principles of good clinical practice [10] and the Declaration of Helsinki [11].

\subsection{Description of Study Stent}

Tetrilimus (Sahajanand Medical Technologies Pvt. Ltd., India) is a novel everolimuseluting coronary stent that combine a L605 cobalt-chromium alloy stent platform with ultra-thin $(60 \mu \mathrm{m})$ strut thickness (Tetrinium; Sahajanand Medical Technologies Pvt. Ltd., India), everolimus drug, and biodegradable drug-carrier polymers. The stent is coated on the conformal surface at a concentration of $1.0 \mu \mathrm{g} / \mathrm{mm}^{2}$ everolimus drug, blended together with biodegradable drug-carrier polymeric matrix of poly-L-lactide, poly L-lactide-co-caprolactone, and polyvinyl pyrrolidone, which controls the release of drug from stent coating. The drug release profile of Tetrilimus stent (Figure 1) suggests that nearly $80 \%$ of everolimus drug is released within one month, while remaining drug is programmed to get released at a slow rate for about 3 months. In addition, the biodegradable polymers retain their properties for a limited period of time and then gradually undergo hydrolysis to degrade into biologically acceptable molecules that are metabolized and removed from the body via normal metabolic pathways. The average coating thickness of Tetrilimus stent is between 3 and $4 \mu \mathrm{m}$. The scanning electron microscopy images of sterile crimped stents and expanded stents shows a smooth and uniform coating surface, without any coating anomalies and defects such as webbing, bridging, and strut-to-strut contact, even after expansion of the stent (Figure 2). During the study period, Tetrilimus everolimus-eluting coronary stent was made available in lengths of $8,12,16,20,24,28,32,36,40,44,48 \mathrm{~mm}$ and diameters of 2.00, 2.25, 2.50, $2.75,3.00,3.50,4.00,4.50 \mathrm{~mm}$.

\subsection{Data Collection and Patient Follow-Up}

Demographic data including age, gender, traditional coronary risk factors, past medical history, and clinical presentation were collected for all patients from hospital records. Details of affected lesions and implanted stents were collected from angiography and angioplasty reports. Adverse events, angina status, and cardiovascular medication in- 


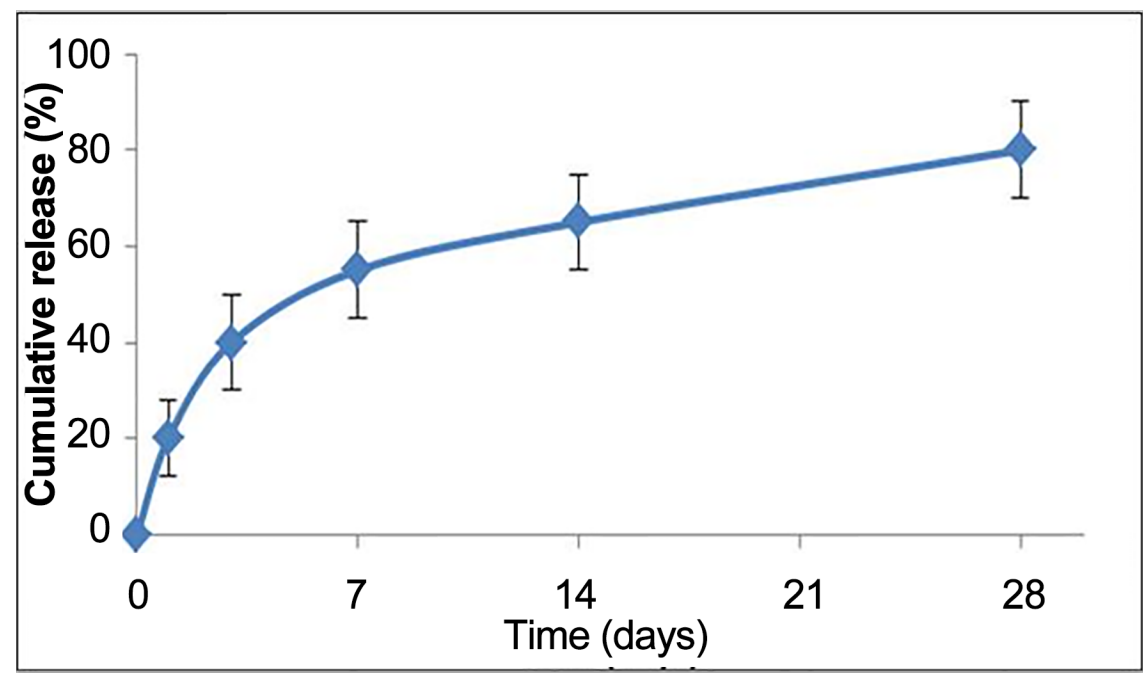

Figure 1. In-vitro drug release profile of Tetrilimus stent.
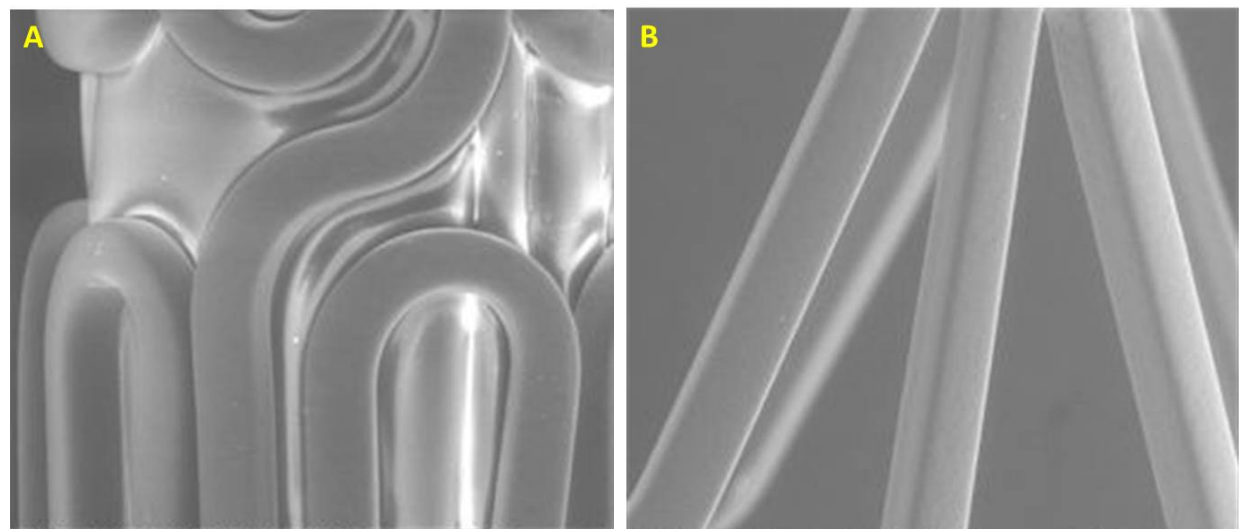

Figure 2. SEM images of (A) crimped Tetrilimus stent and (B) expanded Tetrilimus stent.

take were assessed during hospital stay. In addition, clinical follow-ups were ascertained at 30 days of stent implantation for all patients.

\subsection{Study Endpoints}

The primary endpoint of the study was major adverse cardiac event (MACE), defined as a composite of cardiac death, myocardial infarction, target lesion revascularization, and target vessel revascularization. The secondary endpoints included non-cardiac death in addition to all of the separate components of the primary endpoint. Events of stent thrombosis were determined as additional safety endpoint, which were classified in to definite, probable, and possible stent thrombosis based on the criteria defined by the Academic Research Consortium (ARC) [12].

\subsection{Statistical Analysis}

Continuous variables are presented as mean \pm standard deviation, while categorical variables are presented as frequency and percentages. All data were analyzed using the 
Statistical Package for Social Sciences (SPSS; Chicago, IL, USA) program, version 15.

\section{Results}

\subsection{Demographic Characteristics}

A total of 208 patients were investigated in the present report. Demographic characteristics are summarized in Table 1 . In brief, the mean age of these patients was $57.5 \pm$ 11.9 years, and the study population was predominantly male $(\mathrm{n}=137 ; 65.9 \%)$. Diabetes mellitus, hypertension, smoking, tobacco chewing, and alcoholism were present in 52 (25\%), 97 (46.6\%), 132 (60.8\%), 61 (29.3\%), 29 (13.9\%), and 76 (36.5\%) patients respectively. In addition, 11 (5.3\%) patients had undergone PCI previously.

\subsection{Angiographic and Procedural Characteristics}

A total of 280 Tetrilimus everolimus-eluting stents ( $1.4 \pm 0.5$ stent/patient $)$ were implanted to treat 252 coronary lesions $(1.1 \pm 0.3$ stent/lesion $)$ in the study population. Overall details of lesion and stent characteristics are described in Table 2. About 114 (54.8\%) patients displayed single-vessel coronary disease. Majority of culprit lesions were found in left anterior descending artery (48\%) followed by right coronary artery (33.3\%) and left circumflex artery (18.7\%). Of treated lesions, 170 (67.5\%) were complex (i.e. Type B2/C) and 47 (18.7\%) had total occlusion. The average length and diameter of implanted Tetrilimus everolimus-eluting stents were $25.5 \pm 8.8 \mathrm{~mm}$ and $2.9 \pm$ $0.3 \mathrm{~mm}$ respectively.

\subsection{Clinical Outcomes}

The clinical outcomes during in-hospital and at 30-day follow-up are given in Table 3. It was observed that $2(0.96 \%)$ patients suffered cardiac death during hospital stay. No

Table 1. Baseline characteristics for patients implanted with Tetrilimus stents.

\begin{tabular}{cc}
\hline Demographic details & 208 patients \\
\hline Age (years), mean \pm SD & $57.5 \pm 11.9$ \\
Male, $\mathrm{n}(\%)$ & $137(65.9)$ \\
Diabetes mellitus, n (\%) & $52(25)$ \\
Hypertension, n (\%) & $97(46.6)$ \\
Hypercholesterolemia, n (\%) & $0(0)$ \\
Smoking, n (\%) & $61(29.3)$ \\
Tobacco chewing, n (\%) & $29(13.9)$ \\
Alcoholism, n (\%) & $76(36.5)$ \\
Family history of coronary artery disease, $\mathrm{n}(\%)$ & $0(0 \%)$ \\
Previous MI, n (\%) & $0(0 \%)$ \\
Previous CABG, $\mathrm{n}(\%)$ & $0(0 \%)$ \\
Previous PCI, n (\%) & $11(5.3 \%)$ \\
Previous stroke, n (\%) & $1(0.5 \%)$
\end{tabular}


Table 2. Lesion and stent characteristics for patients implanted with Tetrilimus stents.

\begin{tabular}{|c|c|}
\hline Characteristics & 208 patients/ 252 lesions \\
\hline \multicolumn{2}{|c|}{ Disease vessel (208 patients) } \\
\hline Single-vessel disease, $\mathrm{n}(\%)$ & $114(54.8)$ \\
\hline Double-vessel disease, $\mathrm{n}(\%)$ & $82(39.4)$ \\
\hline Triple-vessel disease, $\mathrm{n}(\%)$ & $12(5.8)$ \\
\hline \multicolumn{2}{|c|}{ Target coronary artery (252 lesions) } \\
\hline Left anterior descending artery, $\mathrm{n}(\%)$ & $121(48)$ \\
\hline Right coronary artery, n (\%) & $84(33.3)$ \\
\hline Left circumflex artery, n (\%) & $47(18.7)$ \\
\hline \multicolumn{2}{|c|}{ Lesion details (252 lesions) } \\
\hline Type $A^{\star}, \mathrm{n}(\%)$ & $17(6.7)$ \\
\hline Type B1*, n (\%) & $65(25.8)$ \\
\hline Type B2*, n (\%) & $44(17.5)$ \\
\hline Type $C^{\star}, \mathrm{n}(\%)$ & $126(50.0)$ \\
\hline Total occlusion, $\mathrm{n}(\%)$ & $47(18.7)$ \\
\hline \multicolumn{2}{|c|}{ Stent details (280 stents) } \\
\hline No. of stents deployed per patient, mean \pm SD & $1.3 \pm 0.5$ \\
\hline No. ofstents deployed per lesion, mean \pm SD & $1.1 \pm 0.3$ \\
\hline Stent length $(\mathrm{mm})$, mean $\pm \mathrm{SD}$ & $25.5 \pm 8.8$ \\
\hline Stent diameter $(\mathrm{mm})$, mean $\pm \mathrm{SD}$ & $2.9 \pm 0.3$ \\
\hline
\end{tabular}

${ }^{*}$ According to American College of Cardiology (ACC)/American Heart Association (AHA) lesion morphology criteria.

Table 3. Clinical outcomes for 208 patients implanted with Tetrilimus stents.

\begin{tabular}{ccc}
\hline Demographic details & In-hospital & At 30-day follow-up \\
\hline Death from any cause, n (\%) & $2(0.96 \%)$ & $2(0.96 \%)$ \\
Cardiac death, n (\%) & $2(0.96 \%)$ & $2(0.96 \%)$ \\
Noncardiac death, n (\%) & $0(0 \%)$ & $0(0 \%)$ \\
Myocardial infarction, n (\%) & $0(0 \%)$ & $0(0 \%)$ \\
Target lesion revascularization, n (\%) & $0(0 \%)$ & $0(0 \%)$ \\
Target vessel revascularization, n (\%) & $0(0 \%)$ & $0(0 \%)$ \\
Overall stent thrombosis ${ }^{\dagger}, \mathrm{n}(\%)$ & $0(0 \%)$ & $0(0 \%)$ \\
Definite stent thrombosis, $\mathrm{n}(\%)$ & $0(0 \%)$ & $0(0 \%)$ \\
Probable stent thrombosis, $\mathrm{n}(\%)$ & $0(0 \%)$ & $0(0 \%)$ \\
Possible stent thrombosis, $\mathrm{n}(\%)$ & $0(0 \%)$ & $2(0.96 \%)$ \\
\hline Major adverse cardiac events, $\mathrm{n}(\%)$ & $2(0.96 \%)$ &
\end{tabular}

${ }^{\dagger}$ According to the Academic Research Consortium (ARC) criteria. 
other major adverse cardiac events were reported till 30-day follow-up. The resultant major adverse cardiac events at 30-day follow-up were noted in $2(0.96 \%)$ patients. All other patients remained stable and symptom-free at 30-day follow-up. Of significance, event of ARC-defined stent thrombosis or noncardiac death was not reported in any patient till 30-day follow-up.

\section{Discussion}

For this ongoing registry aimed at a long-term follow-up with Tetrilimus everolimuseluting stents, here we present a report of preliminary outcomes with Tetrilimus stents at 30-day follow-up in 208 patients. We noted that the 30-day major adverse cardiac events were reported in $2(0.96 \%)$ patients; both cases owing to in-hospital cardiac deaths. Further, the events of stent thrombosis or noncardiac death were not reported in any patient. It should be noted that standardized definitions were used to define each clinical outcome in the present study [12]. Further, the recruitment of consecutive patients along with minimal exclusion criteria facilitated a representation of "all-comers" population in a "real-world" scenario. Further, the demographic and angiographic characteristics of study population reflected a "real-world" scenario, representing a high-risk population. We are of opinion that results of such registry would provide valuable insights regarding the device performance and clinical outcomes in routine clinical practice.

While inclusion of high-risk and complex patients may partly explain the incidents of major adverse cardiac events in the present study, certain other factors including strut thickness, nature of polymer matrix, and potency or elution kinetics of the antiproliferative drugs may also have a role in clinical outcomes [13]. The utility of biodegradable polymers in the Tetrilimus stent system is considered to reduce the risk of local inflammatory reaction and irritation in the target coronary vessel [13]. In addition to this, Tetrilimus stent also offers advantages of cobalt-chromium stent platform with uniform ultra-thin struts and highly flexible design, which may enhance the deliverability of the stent, particularly in complex and challenging lesions, leading to reduced procedural complications [9]. Further, the Tetrilimus stent system comprises everolimus as an antiproliferative drug, which is most widely established among all antiproliferative drugs used in DES [14].

Everolimus is a macrocyclic lactone with antiproliferative and immunosuppressive effects similar to sirolimus, but is more lipophilic, allowing rapid absorption into the arterial wall at the site of vessel injury. Xience (Abbott Vascular, USA) and Promus (Boston Scientific, USA) are the most commonly used everolimus-eluting coronary stents worldwide [14]. Findings from various clinical studies have already indicated that everolimus-eluting stents has bridged the long-term efficacy of first-generation sirolimus-eluting stents with a long-term safety profile similar to that of bare metal stents [15]-[20]. The superior/non-inferior potency of everolimus drug against other antiproliferative drugs has been well-defined in numerous studies [19] [20] [21] [22]. Further, everolimus-eluting stents have demonstrated excellent long-term results in a wide range 
of patients and lesions including those with diabetes [23], chronic total occlusion [24], bifurcation lesion [25], small vessel lesion [26], and in-stent restenosis [27]. The encouraging safety and efficacy outcomes with everolimus-eluting coronary stents (Xience V; Abbott Vascular, USA) are also established in a study of 1,000 Indian patients with coronary artery disease. The study reported that $3.1 \%$ had composite endpoint of cardiac death and any myocardial infarction, while $0.51 \%$ patients had definite/probable stent thrombosis through a 3-year follow up [28]. Likewise, we believe that the encouraging outcomes in the present study of novel Tetrilimus coronary stents could be due to the use of everolimus as antiproliferative drug and other characteristic features including cobalt-chromium stent platform, ultra-thin strut thickness, and biodegradable polymers. Further follow-up is intended to confirm the long-term outcomes. It should also be noted that the present study was not sponsored by any industry.

Our study also bears certain limitations such as retrospective study design, absence of comparative arm/control, and short follow-up period. Further, the intra-vascular ultrasound (IVUS) or optical-coherence tomography (OCT) data for precise estimation of reference vessel diameter or detection of under expanded and malapposed stents were not obtained due to the retrospective nature of the study and financial constricts. Considering these limitations, findings of the present study should be interpreted with caution. However, we believe that the present study provides useful insights about the promising safety and efficacy of Tetrilimus everolimus-eluting coronary stents. Of note, a long-term follow-up in larger sample population is ongoing.

\section{Conclusion}

Low incidence of major adverse cardiac events and absence of stent thrombosis at early 30-day follow-up indicates that Tetrilimus everolimus-eluting stents may have encouraging safety and efficacy in unselected real-world patients with coronary artery disease, including those with high-risk characteristics and complex lesions.

\section{References}

[1] Stettler, C., Wandel, S., Allemann, S., Kastrati, A., Morice, M.C., Schömig, A., et al. (2007) Outcomes Associated with Drug-Eluting and Bare-Metal Stents: A Collaborative Network Meta-Analysis. Lancet, 370, 937-948. https://doi.org/10.1016/S0140-6736(07)61444-5

[2] Serruys, P.W. and Daemen, J. (2007) Are Drug-Eluting Stents Associated with a Higher Rate of Late Thrombosis than Bare Metal Stents? Late Stent Thrombosis: A Nuisance in Both Bare Metal and Drug-Eluting Stents. Circulation, 115, 1433-1439. https://doi.org/10.1161/CIRCULATIONAHA.106.666826

[3] Marchini, J.F., Manica, A. and Croce, K. (2012) Stent Thrombosis: Understanding and Managing a Critical Problem. Current Treatment Options in Cardiovascular Medicine, 14, 91-107. https://doi.org/10.1007/s11936-011-0155-4

[4] Joner, M., Finn, A.V., Farb, A., Mont, E.K., Kolodgie, F.D., Ladich, E., et al. (2006) Pathology of Drug-Eluting Stents in Humans: Delayed Healing and Late Thrombotic Risk. Journal of the American College of Cardiology, 48, 193-202. https://doi.org/10.1016/j.jacc.2006.03.042

[5] Zhang, Y., Shen, J., Li, Z., Zhu, A., Yuan, Y., Yue, R., et al. (2013) Two-Year Clinical Out- 
comes of Different Drug-Eluting Stents with Different Polymer Coating Strategies in Coronary Artery Heart Disease: A Multi-Centre, Randomised, Controlled Clinical Trial. International Journal of Cardiology, 168, 2646-2652. https://doi.org/10.1016/j.ijcard.2013.03.034

[6] Banker, D., Ahuja, A., Sanadhya, H., Purohit, C., Chandra, S., Sethi, R., et al. (2016) Clinical Performance of Biodegradable Polymer Coated Sirolimus Eluting Stents in Unselected "RealWorld" Population with Coronary Artery Disease-Results from Multi-Centre CORE Registry. Minerva Cardioangiologica, 64, 9-14.

[7] Kastrati, A., Mehilli, J., Dirschinger, J., Dotzer, F., Schühlen, H., Neumann, F.J., et al.(2001) Intracoronary Stenting and Angiographic Results Strut Thickness Effect on Restenosis Outcome (ISAR-STEREO) Trial. Circulation, 103, 2816-2821. https://doi.org/10.1161/01.CIR.103.23.2816

[8] Briguori, C., Sarais, C., Pagnotta, P., Liistro, F., Montorfano, M., Chieffo, A., et al. (2002) In-Stent Restenosis in Small Coronary Arteries: Impact of Strut Thickness. Journal of the American College of Cardiology, 40, 403-409. https://doi.org/10.1016/S0735-1097(02)01989-7

[9] Kawamoto, H., Panoulas, V.F., Sato, K., Miyazaki, T., Naganuma, T., Sticchi, A., et al. (2015) Impact of Strut Width in Periprocedural Myocardial Infarction: A PropensityMatched Comparison between Bioresorbable Scaffolds and the First-Generation SirolimusEluting Stent. JACC Cardiovascular Interventions, 8, 900-909.

https://doi.org/10.1016/j.jcin.2015.02.011

[10] Dixon Jr., J.R. (1998) The International Conference on Harmonization Good Clinical Practice Guideline. Quality Assurance (San Diego, Calif), 6, 65-74.

https://doi.org/10.1080/105294199277860

[11] World Medical Association (2013) World Medical Association Declaration of Helsinki: Ethical Principles for Medical Research Involving Human Subjects. JAMA, 310, 2191-2194. https://doi.org/10.1001/jama.2013.281053

[12] Cutlip, D.E., Windecker, S., Mehran, R., Boam, A., Cohen, D.J., van Es, G.A., et al. (2007) Clinical End Points in Coronary Stent Trials: A Case for Standardized Definitions. Circulation, 115, 2344-2351. https://doi.org/10.1161/CIRCULATIONAHA.106.685313

[13] Puranik, A.S., Dawson, E.R. and Peppas, N.A. (2013) Recent Advances in Drug Eluting Stents. International Journal of Pharmaceutics, 441, 665-679.

https://doi.org/10.1016/j.ijpharm.2012.10.029

[14] Townsend, J.C., Rideout, P. and Steinberg, D.H. (2012) Everolimus-Eluting Stents in Interventional Cardiology. Journal of Vascular Health and Risk Management, 8, 393-404.

[15] Serruys, P.W., Ong, A.T., Piek, J.J., Neumann, F.J., van der Giessen, W.J., Wiemer, M., et al. (2005) A Randomized Comparison of a Durable Polymer Everolimus-Eluting Stent with a Bare Metal Coronary Stent: The SPIRIT First Trial. EuroIntervention, 1, 58-65.

[16] Claessen, B.E., Beijk, M.A., Legrand, V., Mastali, K., Wang, J.C., Caputo, R., et al. (2009) Two-Year Clinical, Angiographic, and Intravascular Ultrasound Follow-Up of the XIENCE V Everolimus-Eluting Stent in the Treatment of Patients with De Novo Native Coronary Artery Lesions: The SPIRIT II Trial. Circulation: Cardiovascular Interventions, 2, 339-347. https://doi.org/10.1161/CIRCINTERVENTIONS.108.831800.108.831800

[17] Stone, G.W., Rizvi, A., Newman, W., Mastali, K., Wang, J.C., Caputo, R., et al. (2010) Everolimus-Eluting versus Paclitaxel-Eluting Stents in Coronary Artery Disease. The New England Journal of Medicine, 362, 1663-1674. https://doi.org/10.1056/NEJMoa0910496

[18] Stone, G.W., Rizvi, A., Sudhir, K., Newman, W., Applegate, R.J., Cannon, L.A., et al. (2011) Randomized Comparison of Everolimus- and Paclitaxel-Eluting Stents. 2-Year Follow-Up 
from the SPIRIT (Clinical Evaluation of the XIENCE V Everolimus Eluting Coronary Stent System) IV Trial. Journal of the American College of Cardiology, 58, 19-25.

https://doi.org/10.1016/j.jacc.2011.02.022

[19] Velders, M.A., Hofma, S.H., Brouwer, J., de Vries, C.J., Queré, M. and van Boven, A.J. (2014) Two-Year Results of an Open-Label Randomized Comparison of Everolimus-Eluting Stents and Sirolimus-Eluting Stents. PloS ONE, 8, e64424.

https://doi.org/10.1371/journal.pone.0064424

[20] Park, K.W., Chae, I.H., Lim, D.S., Han, K.R., Yang, H.M., Lee, H.Y., et al. (2011) Everolimus-Eluting versus Sirolimus-Eluting Stents in Patients Undergoing Percutaneous Coronary Intervention: The EXCELLENT (Efficacy of Xience/Promus versus Cypher to Reduce Late Loss after Stenting) Randomized Trial. Journal of the American College of Cardiology, 58, 1844-1854. https://doi.org/10.1016/j.jacc.2011.07.031

[21] Smits, P.C., Kedhi, E., Royaards, K.J., Joesoef, K.S., Wassing, J., Rademaker-Havinga, T.A., et al. (2011) 2-Year Follow-Up of a Randomized Controlled Trial of Everolimus- and Paclitaxel-Eluting Stents for Coronary Revascularization in Daily Practice. COMPARE (Comparison of the Everolimus Eluting XIENCE-V Stent with the Paclitaxel Eluting TAXUS LIBERTÉ Stent in All-Comers: A Randomized Open Label Trial). Journal of the American College of Cardiology, 58, 11-18. https://doi.org/10.1016/j.jacc.2011.02.023

[22] Serruys, P.W., Silber, S., Garg, S., van Genus, R.J., Richardt, G., Buszman, P.E., et al. (2010) Comparison of Zotarolimus-Eluting and Everolimus-Eluting Coronary Stents. The New England Journal of Medicine, 363, 136-146. https://doi.org/10.1056/NEJMoa1004130

[23] Kim, W.J., Lee, S.W., Park, S.W., Kim, Y.H., Yun, S.C., Lee, Y.J., et al. (2011) Randomized Comparison of Everolimus-Eluting Stent versus Sirolimus-Eluting Stent Implantation for de Novo Coronary Artery Disease in Patients with Diabetes Mellitus (ESSENCEDIABETES): Results from the ESSENCE-DIABETES Trial. Circulation, 124, 886-892. https://doi.org/10.1161/CIRCULATIONAHA.110.015453

[24] Valenti, R., Vergara, R., Migliorini, A., Parodi, G. Buonamici, P., Cerisano, G. et al. (2011) Comparison of Everolimus-Eluting Stent with Paclitaxel-Eluting Stent in Long Chronic Total Occlusions. American Journal of Cardiology, 107, 1768-1771. https://doi.org/10.1016/j.amjcard.2011.01.063

[25] Herrador, J.A., Fernandez, J.C., Guzman, M. and Aragon, V. (2011) Comparison of Zotarolimus- versus Everolimus-Eluting Stents in the Treatment of Coronary Bifurcation Lesions. Catheterization and Cardiovascular Interventions. 78, 1086-1092. https://doi.org/10.1002/ccd.22991

[26] Almalla, M., Schroder, J.W., Pross, V., Stegemann, E., Marx, N. and Hoffmann, R. (2011) Everolimus-Eluting versus Paclitaxel-Eluting Stents for Treatment of Bare Metal Stent Restenosis. American Journal of Cardiology, 108, 518-522. https://doi.org/10.1016/j.amjcard.2011.03.080

[27] Cannon, L.A., Simon, D.I., Kereiakes, D., Jones, J., Mehran, R., Kusano, H., et al. (2012) The XIENCE Nano ${ }^{\mathrm{TM}}$ Everolimus Eluting Coronary Stent System for the Treatment of Small Coronary Arteries: The SPIRIT Small Vessel Trial. Catheterization and Cardiovascular Interventions, 80, 546-553. https://doi.org/10.1002/ccd.23397

[28] Seth, A., Patel, T.M., Stuteville. M., Kumar, R. Mullasari, A.S., Kaul, U. et al. (2014) ThreeYear Data from the XIENCE V INDIA Study: Safety and Efficacy of XIENCE V in 1000 Real World Indian Patients. Indian Heart Journal, 66, 302-308. https://doi.org/10.1016/j.ihj.2014.03.007 
Submit or recommend next manuscript to SCIRP and we will provide best service for you:

Accepting pre-submission inquiries through Email, Facebook, LinkedIn, Twitter, etc. A wide selection of journals (inclusive of 9 subjects, more than 200 journals)

Providing 24-hour high-quality service

User-friendly online submission system

Fair and swift peer-review system

Efficient typesetting and proofreading procedure

Display of the result of downloads and visits, as well as the number of cited articles

Maximum dissemination of your research work

Submit your manuscript at: http://papersubmission.scirp.org/

Or contactwjcd@scirp.org 